\title{
Radiation Protection Management for Patients Treated with Iodine-131 in Islamic Cultures
}

\author{
Jahangir Ahmad Satti, PhD \\ Kelantan, Malaysia
}

\begin{abstract}
Nutritional requirements, religious prohibitions, and medical restrictions demand modification in the use of edible items, including drugs. Unique social, traditional, and economic conditions in the Islamic world require resolution of certain issues that have not been addressed so far. Protection from ionizing radiation is one of them. The Islamic code of life is different from the western lifestyle. A radioactive-carrying patient poses different problems to a community where regular collective prayers (șalăh), extended visits paid to a sick fellow, and frequent gatherings are unavoidable. Furthermore, economic conditions also influence the risk of radiation exposure that contributes to radiation dose. These and other factors demand a modification in the protocol of radiation protection that are basically modeled around a western lifestyle. We have discussed the issues of patients treated with iodine-131 for thyroid problems in IsIamic culture.
\end{abstract}

Key words: iodine-131, iodine-131 uptake, radiation exposure, Islam.

$\mathbf{T}$ he use of radio iodine in diagnostic and therapeutic radiology is common. There has not been any significant evidence of radioiodine-13I ('13I) side effects in patients treated for hyperthyroidism. However, for cancer patients treated with ${ }^{31} \mathrm{I}$, an excess in the incidence of and mortality from leukemia, bladder, kidney, and possible breast cancer was found. The thyroid may uptake up to

Presented at the Third International and 28th Annual Convention of the Islamic Medical Association of North America, July 9-14, 1995, Kuala Lumpur: Malaysia.

From the Department of Radiology

School of Medical Sciences

Universiti Sains Malaysia

Kelantan, Malaysia

Reprint Requests: Jahangir Ahmad Satti, PhD

Department of Radiology

School of Medical Sciences

Universiti Sains Malaysia

16150 Kubang Ketian

Kelmtan, Malaysia
$35 \%$ of administered iodine, whereas renal, thrombi, and adrenals also uptake ${ }^{131}$ I. Brindle suggested that there is no need to pose any upper limit of ${ }^{131}$ I activity for outpatient treatment regarding contamination hazards. ${ }^{2,3}$

The Maximum Permissible Dose (MPD) limits have been in continuous review for a century in light of every new radiation data and finding. Meanwhile, a tremendous change also has occurred in the public attitude toward radiation protection. The Effective Dose Equivalent (EDE) set in 1960 became obsolete when the International Commission on Radiation Protection (ICRP) published recommendations in 1977.4 The U.S. Environmental Protection Agency (EPA) issued "Radiation Protection Guidance" to Federal Agencies for occupational exposure in 1987. The National Council for Radiation Protection and Measurement (NCRP) and the ICRP revised their recommendations in $1991.5,6$

Culver and Dworkin measured radiation exposure on 59 patients and suggested adopting a radiation protection policy to fit the requirements. ${ }^{7}$ Dydek and Blue found that excretion of ${ }^{131}$ I into human breast milk requires a much longer period than previously reported. ${ }^{8}$ After the publication of Dydek and Blue's report, Remney et al admitted that 
(heir "original recommendations for resuming nursing fol-

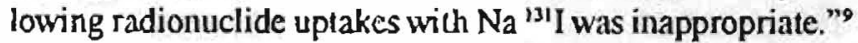
Although, a review of the secretion of radionuclides in breast milk was made by Mountford and Coakley, ${ }^{10}$ who found there was no definite time period for stopping breast feeding recommended in association with ${ }^{\mid{ }^{\prime}} \mathrm{I}$.

Hilditch et al measured the thyroidal retention of ${ }^{131} I$ in 77 thyrotoxic patients and proposed that body radioactivity could be measured based on their data." Louge et al found that patients who receive less than $3.7 \mathrm{G} \mathrm{Bq}$ (Giga Becquerel or 100 milli Curie) ${ }^{131}$ I tend to have iodine uptake. ${ }^{12}$ This dose rate affecting thyroid uptake was further confirmed in a study by Samuel and Rajashekharrao. ${ }^{13}$ There have been studies of radio iodine hazards that were the result of thyroid uptake apart from applications of diagnostic and therapcutic purposes. ${ }^{14}$

The use of radio iodine for diagnostic and therapeutic purposes is popular, especially in developing countries, due 10 its easy production, half life, uptake, and easy use in treating certain diseases. ${ }^{15}$ As the uptake of ${ }^{31} I$ by thyroid is significant, the risk of cancer due to these radiation also is significant, especially in women whose breasts are exposed to thyroid radionuclide due to close proximity. ${ }^{16}$ There are other areas where ${ }^{131} \mathrm{I}$ is used for different purposes. ${ }^{17,18}$ The different therapeutic uses of radio iodine eventually end up by the uptake of thyroid that becomes radioactive due to it. As the annual radiation dose limits are made more strict, it becomes inevitable to modify radiation protection prolocols for the radiation workers, general public, and patients. The new dose limits recommended by ICRP and NCRP for public is I milli Sievert ( $\mathrm{mSv}$ ) in normal cases and $5 \mathrm{mSv}$ in infrequent exposures. ${ }^{5.6}$

\section{Materials and Methods}

The equivalent dose rate to soft tissuc exposed by a point source containing $A \mathrm{MBq}^{131} \mathrm{I}$ at a distance of $d$ meter is ${ }^{19} \mathrm{D}$ $=1.558 \times 10^{-5} \mathrm{~A} / \mathrm{d}^{2} \mu \mathrm{Sv} / \mathrm{sec}$.

The effective half life, $T_{\text {asf }}$ of '1'I is 6.35 days. As Wassermann and Klopper ${ }^{20}$ estimated, the total dose to a subject irradiated at a constant distance $d$ over a period $T$ for a fraction $\int$ per day or week, the total dose yield is

$\mathrm{D}(\mathrm{mSv})=$ Cfu A T $\mathrm{ent}^{\prime} \mathrm{d}^{2}\left(1-\mathrm{e}^{(-0.693 \mathrm{rTer})}\right)$ where $C$ is $8.095 \times 10^{-5}$ for $T$, and $T$ is time in hours. $A$ is the activity of ${ }^{131} I$ administered and $u$ is the fraction concentrated in the thyroid.

Using the above method, we estimated radiation doses received by Muslim worshippers from a fellow worshipper who was administered $30 \mathrm{mCi}$ dose of ${ }^{131} \mathrm{I}$ for thyrotoxicosis. The estimates were for normal prayer times and extended prayer periods during the month of Ramadan. It has been considered that the same fellow worshipper offers prayers with the ${ }^{131}$ I treated patient for five times a day at a distance of $0.5 \mathrm{~m}$ for more than two hours per day. The total radiation dose received by the fellow worshipper over 14 days will be $0.03 \mathrm{mSv}$, which is far below the annual permissible dose level for general public. Iodine ${ }^{31}$-treated patients should not be barred from offering prayer in mosque when treated for thyotoxicosis.

Children sharing same bed with the ${ }^{131}$ I-treated patient, received up to $0.2 \mathrm{~m} \mathrm{~Sv}$ of radiation dose at a distance of 0.2 meter for a period of eight days up to eight hours per day.

\section{Recommendation}

Any patient receiving less than $12 \mathrm{mCi}{ }^{131} \mathrm{I}$ can be allowed to go home provided he or she observes radiation protection rules. Children and pregnant women should not sleep in the same room for one week. Frequent visits by children (up to 18 years ago) and pregnant women should not be allowed. Persons sharing the same room must keep a distance of at least 1 meter for first four days. Any patient receiving more than $12 \mathrm{MCi}^{131}$ I treatment should be kept in hospital for first four days. After that period, the patient may be allowed to go home with above radiation protection protocol. A nursing mother receiving a dose of $10 \mathrm{mCi}$ dose of ${ }^{131}$ I needs to abstain breast feeding for 120 days. It is highly unlikely that nursing can be resumed soon with small doses of ${ }^{131}$ I. Those women who prefer to breast feed their babies should tell their physician about their intentions and request alternate methods or imaging procedures such as technetium-99 pertechnetate if it is ${ }^{131}$ I unavoidable. In the case of treatment, babies should not be fed for the above desired period since the administration of the last radioactive dose.

\section{Discussion}

Radiation protection issues for patients treated with iodine isotope ${ }^{13}$ I for thyroid diseases pose different questions in Islamic culture than in the western society. Patients can swallow doses of ${ }^{131} \mathrm{I}$ of up to 30 milli Curic (mCi) at an interval of two weeks.

Patients receiving ${ }^{131} \mathrm{I}$ treatment are generally allowed to go home in the developed countries because it is assumed that a separate bedroom would be available to a radio iodine treated patient. Such a facility is not yet enjoyed by the majority of people in the developing countries where a medium size room may be shared by more than four persons. Furthermore, a devout Muslim offers regular prayer (șalāh) five times a day with other worshippers who can be at a distance as close as touching each other. The probability of radiation exposure to the thyroid of a fellow worshipper is more likely. The risk may be maximum during the fasting month (Ramadan) when extended prayers are offered. Muslims do live in a joint family system and, as tradition, children prefer to sleep in the same bed with their parents and grandparents. Apart from economic constraints, this tradition has deep roots in the Indian subcontinental culture. It becomes difficult to implement radiation protection procedures in such circumstances due to emotional and traditional reasons. It has further been observed that Muslim women prefer to breast feed their babies where the excretion of radio iodine in breast milk can be significant. These cultural, economical, and traditional anomalies in develop- 
ing countries in general and among Muslims in particular demand modification in radiation protection policy. The above-stated radiation protection protocol has been worked out for patients treated with iodine-131 in Islamic cultures.

The Islamic culture has different lifestyle. It has unique socio-economic problems and philosophical approach. Liquor, pork, and certain foods are prohibited. The main problem is to modify or invent a new strategy that suits the Islamic culture. For instance, insulin injections are vital for a diabetic. Almost all of the insulin products are derived from pigs. ${ }^{21}$ Pork or its products are not allowed (harām) for Muslims. There is a need to conduct research for substitutes from other animals or alternative medicines that do not conflict with one's belief. The issue of radio iodine is similar where a devout Muslim needs to be among his fellow beings for some period following the uptake.

\section{References}

1. ICRP: "Protection of the patient in nuclear medicine," Pergamon Press, NY, 1993.

2. Buchan RCT; Brindle JM: Radio iodine therapy to outpalient - the contamination hazard, Br J Radiol 1970;43:479-82. 3. Buchan RCT, Brindle JM: Radio iodine therapy to outpatient - the radiation hazard, Br J Radiol 1971;44:973-75. 4. IRCP: "Recommendations of the International Commission on Radiation Protection," ICRP Report-26, 1977.

5. NCRP: "Recommendations on limits for exposure to ionizing radiation," 1991 Report-91, Bethesda, MD.

6. ICRP: "Recommendations of the ICRP," Publication-60, 1991;21(1-3).

7. Culver $\mathrm{CM}$ and Dworkin HJ: "Radiation safety considerations for post iodine-131 hyperthyroid therapy," J of Nucl Med 1991;32:161-73.

8. Dydek GJ and Blue PW: "Human breast milk excretion of iodine-131 following diagnostic and therapeutic administration to a lactating patient with Graves' disease. J Nucl Med 1988;29:407-10.

9. Romney B, Nickoloff EL, Esser PD: "Excretion of radionuclide in breast milk" (editorial). J Nucl Med 1989;30:124-6.

10. Mountford PJ, Coakley AJ: "A review of the secretion of radioactivity in human breast milk: data, quantitative analysis and recommendation," Nucl Med Comm 1989;10:15-27.

11. Hilditch TE, Connell, JMC, Davies DL, et al: Radiological protection guidance for radioactive patients - new data for therapeutic ${ }^{131}$ I. Nucl Med Comm 1991;12:485-95. 12. Logue JP, Tsang RW, Btierley J D, et al: "Radio iodine ablation of residual tissue in thyroid cancer: relationship between administered activity, neck uptake and outcome," $\mathrm{Br} J$ of $\operatorname{Rad} 1994 ; 67: 1127-31$.

13. Samuel AM, Rajashekharrao B: Radio iodine therapy for well-differelitiated thyroid cancer: a quantitative dosimetric evaluation for remnant thyroid ablation after surgery." J Nucl Med 1994;35:1944-50.

14. Kaicheng $T$, Changqing Y, Peigin Z, Yi fen G, Youbin J, Ruihua W: Estimation of ${ }^{131} I$ intake and thyroid dose in persons irradiated in a reactor accident. J Radiol Prot 1994:4:337-43.

15. Vera-Ruiz H: Radiopharmaceuticals as therapeutic agents in medical care and treatment. IAEA Bulletin 1993;35:24-7.

16. Boice J D; Land CE; Shore RE; Norman JE; Tokunaga M: Risk of breast cancer following low-dose radiation exposure. Radiology 1979;131:589-97.

17. Bomanji J, Britton KE, Ur E, Hawkins L, Grossman $A B, B e s s e r ~ G$ : Treatment of malignant phaeochromocytoma paraganglioma and carcinoid tumors with 131-I metaiodobenzylguandine. Nucl Med Comm 1993;14: 856961.

18. Mairs RJ, Gaze MN, Watson DG, Skellern GC, Constable P. McKellar K, Owens J, Vaidyanathan G, Zalutsky MR: Carrier-free ${ }^{131}$ I metaiodobenzylguanidine: Comparison of production from meta-diazobenzylguadine and from meta-trimethylsilylbenzylguanidine. Nucl Med Comm 1994;15:268-74.

19. Wassermaim H, Groenewald W: Air kerma rate constants for radionuclides. Eur J Nucl Med, 1988;4:569-71. 20. Wasserman HJ, Klopper JF: Analysis of radiation doses received by the public from ${ }^{131}$ I treatment of thyrotoxic outpatients. Nucl Med Comm. 1993;14:756-60.

21. Jayasuriya A: Update on the Pharmaceutical Industry. Medicina Alternativa, Sri Lanka. 1993. 